We welcome letters to the Editor concerning articles which have recently been published. Such letters will be subject to the usual stages of selection and editing; where appropriate the authors of the original article will be offered the opportunity to reply.

Letters should normally be under $\mathbf{5 0 0}$ words in length, doublespaced throughout, signed by all authors and fully referenced. The edited version will be returned for approval before publication.

\section{BRACHIAL PLEXUS BIRTH PALSIES}

Sir,

I read with interest the article in your November 1992 issue by Covey et al entitled 'Modification of the L'Episcopo procedure for brachial plexus birth palsies' (1992; 74-B:897-901). In the discussion, they refer to the series of Hoffer et al (1978) and compare their results, after transfer of tendons to the rotator cuff, with those of their own technique. They state that two of Hoffer's 11 patients had less movement than before surgery.

Review of the paper by Hoffer et al shows that all patients had an increase in active external rotation, and only one had a decrease in active abduction. The actual results reported in this case show an increase from $0^{\circ}$ to $50^{\circ}$ in external rotation with an increase in power, and a decrease in abduction from $130^{\circ}$ to $120^{\circ}$. Taken together these changes do not represent the poor result which is implied by Covey et al.

It appears that Hoffer et al actually had better overall results than Covey et al, although the exclusion of patients under two years and over eight years of age, and those with whole plexus injuries from Covey's series do make the results comparable.

R. D. A. DODDS, $O B E$, FRCS

St Mary's Hospital

London, UK.

Covey DC, Riordan DC, Milstead ME, Albright JA. Modification of the L'Episcopo procedure for brachial plexus birth palsies. $J$ Bone Joint Surg [Br] 1992; 74-B:897-901.

Hoffer MM, Wickenden R, Roper B. Brachial plexus birth injuries: results of tendon transfers to the rotator cuff. $J$ Bone Joint Surg [Am] 1978; 60-A :691-5.

\section{Authors' reply:}

We appreciate Mr Dodds' comments regarding our paper, but we did not state in our discussion, nor did we intend to infer, that any patients in the series of Hoffer et al had a poor result. Nor did we compare our results with those of Hoffer et al since the patient populations were not the same. As Mr Dodds indicates, our series included one two-year-old patient and five who were over eight years of age at the time of surgery. Hoffer et al had only one patient older than eight years, and their youngest patient was three years old. One of our patients had whole plexus palsy. The average age of our patients was older than in the series reported by Hoffer et al.

It is true that one of Hoffer's patients did lose only a small amount of abduction and another patient failed to gain external rotation to neutral. Our wording was inexact in this regard.

We feel that the procedure reported by Hoffer et al provides excellent treatment, but we also consider that that reported by

(C) 1993 British Editorial Society of Bone and Joint Surgery

0301-620X/93/4621 \$2.00

J Bone Joint Surg [ Br] 1993; 75-B:666-7. us has significant merit: the operation is performed predominantly through an axillary incision, and achieves direct tendonto-tendon repair.

D. C. COVEY, MD

Naval Hospital

Bremerton

Washington, USA.

J. A. ALBRIGHT, MD

LSU School of Medicine

Shreveport

Louisiana, USA.

\section{TIBIAL DYSPLASIA}

Sir,

I read with interest the article in your November 1992 issue by Pattinson and Fixsen on 'Management and outcome in tibial dysplasia' (1992; 74-B:893-6) and was surprised that the bibliography did not include the largest series reported in the literature to date. This was published in the American Journal of Bone and Joint Surgery in February 1989 (1989; 71-A :278-87) and represented the cumulative experience of several paediatric orthopaedic surgeons from mid-central USA.

Our findings would have added to the discussion of pathology, classification and, most importantly, treatment. Specifically, page 286 of our article refers to a comprehensive treatment protocol based on experience of 71 limbs. We found that the classification system of either Jones et al (1978) or Kalamchi and Dawe (1985) will work, but we prefer the former as it includes more of the unique characteristics of the various types of congenital tibial dysplasia.

\section{P. L. SCHOENECKER, MD}

Shriners Hospital for Crippled Children

St Louis

Missouri, USA

Jones D, Barnes J, Loyd-Roberts GC. Congenital aplasia and dysplasia of the tibia with intact fibula: classification and management. $J$ Bone Joint Surg [ Br] 1978; 60-B:31-9.

Kalamehi A, Dawe RV. Congenital deficiency of the tibia. J Bone Joint Surg [Br] 1985; 67-B:581-4.

Pattinson RC, Fixsen JA. Management and outcome in tibial dysplasia. J Bone Joint Surg [Br] 1992; 74-B:893-6.

Schoenecker PL, Capelli AM, Millar EA, et al. Congenital longitudinal deficiency of the tibia. J Bone Joint Surg [ Am] 1989; 71-A:278-87.

Author's reply:

Thank you very much for sending me a copy of Dr Schoenecker's letter of 22 December 1992. I would like to thank him for drawing my attention to the excellent article published in the February 1989 issue of the American Journal of Bone and Joint Surgery, and to apologise that Mr Pattinson and I failed to quote this paper. Clearly, this is a major article with the largest group of patients reported in the English literature.

I was delighted that we reached much the same conclusions, and was interested to note that they preferred the Jones classification which was developed at The Hospital for Sick Children. Type III has always given difficulty; it is interesting that Dr Schoenecker's series of patients also showed proximal development of the tibia, which was our reason for using the classification into three groups as suggested by Kalamchi and Dawe, rather than that developed at our own hospital.

J. A. FIXSEN, MChir, FRCS

The Hospital for Sick Children

Great Ormond Street

London, UK. 